\title{
Cross-cultural Adaptation of an Instrument to Assess Coparenting: Coparenting Relationship Scale
}

\author{
Thaís Ramos de Carvalho ${ }^{1}$ \\ Elizabeth Joan Barham ${ }^{1}$ \\ Carolina Duarte de Souza ${ }^{2}$ \\ Elisangela Böing² \\ Maria Aparecida Crepaldi ${ }^{2}$ \\ Mauro Luís Vieira ${ }^{2}$ \\ ${ }^{1}$ Universidade Federal de São Carlos, São Carlos, SP \\ ${ }^{2}$ Universidade Federal de Santa Catarina, Florianópolis, SC
}

\begin{abstract}
Coparenting refers to mothers and fathers articulating their efforts to raise their children. Currently, there are no instruments to measure this construct in Brazil. In this study, the adequacy of a cross-cultural adaptation of the Coparenting Relationship Scale (CRS) (Escala da Relação Coparental - ERC) was evaluated, examining evidence of semantic, conceptual, cultural, idiomatic, operational and measurement equivalence, and face validity. Two independent research groups adapted the CRS and then produced a unified version, completed by 171 couples with at least one child between 4 to 6 years of age. The precision of the subscales, measured using Cronbach's alpha, varied between .16 - .83. Four subscales had good precision in the Brazilian sample, but the precision of the "Division of Labor", "Coparenting Closeness", and "Coparenting Agreement" subscales needs to be improved and additional evidence of the validity of this instrument must be examined, so the CRS can be used in Brazil.

Keywords: coparenting; precision; scale.
\end{abstract}

Adaptação Transcultural de um Instrumento para Avaliar a Coparentalidade: Coparenting Relationship Scale

\section{Resumo}

A coparentalidade envolve a articulação entre mães e pais para criar os filhos. Ainda não existem instrumentos para mensurar este construto, no Brasil. Nesse estudo, foi verificada a adequação de uma adaptação transcultural do Coparenting Relationship Scale (CRS) (Escala da Relação Coparental - ERC), por meio da avaliação das equivalências semântica, conceitual, cultural, idiomática, operacional e de mensuração e da validade aparente. Dois grupos de pesquisa independentes adaptaram a CRS e, depois, produziram uma versão unificada, respondida por 171 casais, com pelo menos um filho de 4 a 6 anos. Os índices de precisão, mensurados por meio do alfa de Cronbach para cada subescala, variaram entre 0,16 e 0,83 . Quatro subescalas apresentaram boa precisão de mensuração da coparentalidade no contexto brasileiro, mas será necessário reformular as subescalas "Divisão de Tarefas", "Proximidade Coparental" e "Concordância Coparental", além de avaliar evidências adicionais de validade, para que a ERC possa ser usada no Brasil.

Palavras-chave: coparentalidade; precisão; escala.

\section{Adaptación Transcultural de un Instrumento para Evaluar Coparentalidad: Coparenting Relationship Scale}

\section{Resumen}

La coparentalidad implica articulación entre madres y padres para criar a los hijos. Todavía en Brasil no existen instrumentos para medir este constructo. En este estudio fue verificada la adecuación de una adaptación transcultural del Coparenting Relationship Scale (CRS) (Escala da Relação Coparental - ERC), por medio de evaluación de equivalencias semántica, conceptual, cultural, idiomática, operativa, de medición y validez aparente. Dos grupos de investigación independientes adaptaron CRS y, después, produjeron una versión unificada, respondida por 171 parejas con por lo menos un hijo de 4 a 6 años. Los índices de precisión, medidos por medio de alfa de Cronbach para cada subescala, oscilaron entre 0,16 y 0,83 . Cuatro subescalas presentaron buena precisión de medición de coparentalidad en el contexto brasileño, pero será necesario reformular las subescalas "División de Tareas", "Proximidad Coparental" y "Concordancia Coparental", además de evaluar evidencias adicionales de validez, para que la ERC pueda ser utilizada en Brasil.

Palabras-clave: coparentalidad; precisión; escala.

A series of economic and cultural changes have led to structural and functional changes in family life (Biasoli-Alves, 2000), which have contributed to the development of new patterns of interaction between men and women, with implications for maternal and paternal roles and for their collaboration with each other in raising their children, known as coparenting. Coparenting was defined by Feinberg (2003) as the way 
in which parents relate to one another in order to perform their parental roles. This relationship arises when two individuals assume responsibilities for raising a particular child, and it is influenced by the broader social and cultural context.

After gathering empirical evidence from several studies, Feinberg $(2002,2003)$ proposed a model to understand coparenting, the Coparenting Internal Structure Model, distinguishing its internal dimensions and factors from the ecological context in which the coparenting relationship is inserted. The coparenting relationship affects how parents understand their parental responsibilities, how they coordinate their involvements, whether there is mutual support, and how they manage conflicts related to the task of educating their children. In Feinberg's theoretical model, four components are highlighted: (a) agreement or disagreement on childrearing issues, (b) support or undermining of the partner's parenting, (c) division of child-related labor and (d) joint management of family interactions.

The coparenting relationship has been measured and evaluated in the international literature using different methods, such as questionnaires, interviews and observations (Frizzo, Kreutz, Schmidt, Piccinini, \& Bosa, 2005). However, no instruments developed to assess this construct were found in the Brazilian literature. Thus, Carvalho and Barham (2016) compared the psychometric properties of instruments developed in other countries, to choose the one that seemed most appropriate to undergo a cross-cultural adaptation process for use in Brazil. Eight instruments were submitted to a detailed analysis, comparing their characteristics and evidence of their validity. The Parenting Alliance Measure (PAM), the Coparenting Inventory for Parents and Adolescents (CI-PA) and the Coparenting Relationship Scale (CRS) were the instruments with the most robust evidence of precision and validity. Based on this analysis, the CRS, created by Feinberg, Brown and Kan (2012), was selected to go through the cross-cultural adaptation process, since unlike the PAM, it was an instrument developed based on the coparenting model proposed by Feinberg, adopted as a reference in this study. In addition, the CRS seemed to have an advantage over the CI-PA, since the latter was designed to be used with mothers, fathers and children of a particular age group (adolescents), making it difficult to use this instrument in the development and assessment of early interventions.

The CRS, created in the United States, aims to evaluate coparenting and is comprised of seven subscales, based on the four more general domains of coparenting proposed by Feinberg (2003). The first domain, which refers to agreements or disagreements regarding parental practices and issues related to child rearing, is represented by the subscale "Coparenting Agreement". The second domain, involving the support or undermining of the partner's parenting role, is assessed using three subscales: "Coparenting Support", "Endorsement of Partner's Parenting" and "Coparenting Undermining". The subscale "Coparenting Support" is related to the perception of the support received from the partner, while the subscale "Endorsement of Partner's Parenting" refers to the perception of one's own positive attitudes towards the partner's parenting. The third domain, which covers the joint management of family interactions, is represented by the "Exposure to Conflict" subscale, which is used to verify if the parents have disagreements on how to raise their child, in the presence of this child. The fourth domain, which involves the parents' division of childrearing work, is evaluated with the "Division of Labor" subscale, which aims to measure the satisfaction of each of the parents with the contributions and involvement of their partner in childrearing tasks. Finally, the authors created an additional subscale, "Coparenting Closeness", in order to measure the extent to which coparenting interactions contribute to perceptions of increased intimacy and strengthening of the couple's relationship.

In a longitudinal study, Feinberg et al. (2012) evaluated a sample of couples using the CRS at three different time points: when their children were 6 months of age (collecting full data with 152 mothers and 149 fathers), 1 year old, and 3 years of age (retaining 139 mothers and 129 fathers from the initial sample). The subscale precision indices were examined for each wave of the data collection, leading to the following results: Coparenting Agreement (alphas ranging between .66 and .74), Coparenting Closeness (.75 - .83), Coparenting Support (.86 - .89), Endorsement of Partner's Parenting (.61- .88), Coparenting Undermining $(.80-.85)$ and Exposure to Conflict (.81 - .90). For the Division of Labor subscale, composed of only two items, the authors presented values for each time point, for the correlation between these items, which ranged between .33 and .59. A confirmatory factor analysis for the CRS, using two independent samples, has not been reported in the published literature, but Feinberg et al. noted that the factor structure of the CRS, for each wave of data collection, remained stable over time, indicating that the relationship among concepts that underlie coparenting did not change during the first three years of parenting. The CRS scores were 
also significantly correlated with results on instruments used to evaluate the quality of the marital relationship, depressive symptoms (for mothers and for fathers), child adjustment and negative affect.

\section{Cross-cultural Adaptation of Psychometric Instruments}

The term cross-cultural adaptation refers to a process that involves specific methodological procedures to adjust a psychometric instrument developed for a particular culture, so that it can be used in a different culture, while maintaining the equivalence between the original instrument and its adapted version (Machado, 2013). In this sense, the possibility of using a measure developed in another language in a different country involves more than simply translating items; it requires efforts to evaluate language equivalence issues and to assess the equivalence of the meaning of the behaviors described in the instrument, considering the cultural context in which the instrument was constructed and the cultural context of the second country.

According to Guillemin, Bombardier, and Beaton (1993), adapting a pre-existing measure for a different target population has several advantages: (a) it provides a common measure to investigate an underlying concept in different cultural contexts, enabling comparisons between people from different countries as well as among people from distinct cultural-linguistic groups, who live in the same country, (b) when describing national norms and practices, it permits the inclusion of people who live in the country but who do not speak the official language, avoiding the frequent bias of only representing the country's dominant culture, and (c) it is less expensive and time consuming than creating a new measure. However, although investments to adapt instruments may be lower than those needed to create a new measure, these authors comment that cross-cultural adaptation also requires a great deal of care and effort, as it involves a large number of people and is time-consuming.

\section{Steps in the Cross-cultural Adaptation Process}

The steps followed in the present study are described based on procedures suggested by Herdman, Fox-Rushby and Badia (1998), Beaton, Bombardier, Guillemin and Ferraz (2000) and Reichenheim and Moraes (2007), involving the assessment of the following types of equivalence: semantic, conceptual, cultural (or experiential), idiomatic, operational and measurement.
To establish semantic equivalence, the content of the original instrument must be translated so that the meaning expressed in the items of the original version and in the wording of the items in the translated version generates similar effects on the respondents of the original culture and on those of the target culture (Reichenheim \& Moraes, 2007). This type of equivalence depends on the convergence of word meaning between the original and the translated version of the instrument, as well as the exclusion of word choices that have more than one meaning and that permit alternative interpretations. This step occurs during the translation and back-translation of instrument (Reichenheim \& Moraes, 2007) and typically requires grammatical changes in the sentence structure of the adapted version of the instrument, such as occurs when working with one language that uses gerunds and another that does not use them (Guillemin et al., 1993).

The verification of conceptual equivalence involves assessing the correspondence between how constructs are measured, using the original instrument, and how well they are measured using the items of the adapted version, as well as the checking for potential differences in the conceptual meaning of the words used in the adapted instrument and the words used in the original the instrument (Beaton et al., 2000). The items may present equivalence in semantic meaning, and at the same time, conceptual differences. The words "brother" and "cousin", for instance, may mean only one degree of kinship in some cultures and have a wider meaning in others (Guillemin et al., 1993). At this point, it is also important to assess the relevance and pertinence of the different domains (or dimensions) that make up the concept of interest in the original cultural context, in the target culture (Reichenheim \& Moraes, 2007).

Cultural equivalence analysis, in turn, involves deciding whether the ideas described in each item, besides being translatable, are also experienced in the target country or culture (Beaton et al., 2000). As such, in this step, it is important to verify if there is a correspondence that goes beyond literal similarity, and that takes into consideration geographic, educational and socioeconomic characteristics that influence the sociocultural context (Reichenheim \& Moraes, 2007). If necessary, the item should be replaced by a similar item that describes a situation that is actually experienced in the target culture (Beaton et al., 2000). The question, "How many hours per week do you spend on leisure activities?", for example, may not be appropriate in a context 
where most people do not have time for or access to leisure opportunities (Guillemin et al., 1993).

In addition to the previous analyses, idiomatic equivalence aims to verify if the idiomatic and colloquial expressions used in the instrument are translatable and, if not, equivalent expressions must be found, to replace them (Guillemin et al., 1993). After analyzing all these dimensions of the wording of each item, it is also important to examine the operational equivalence of the instrument being adapted. This involves evaluating the possibility of using the same format, instructions, organization of the evalutation context, and measurement methods in another culture, considering factors such as the respondents' educational levels, as well as their access to and their familiarity with any technological equipment that is used (e.g., computers). Equivalence is achieved when these elements do not affect the results (Herdman et al., 1998).

After dealing with all the preceding issues, the next requirement is to investigate the measurement equivalence of the adapted instrument, to establish whether its psychometric properties meet or surpass the standards used to define acceptable levels of quality (Herdman et al., 1998). In addition, the psychometric properties of each version of the instrument should be compared (Reichenheim \& Moraes, 2007).

In addition to these steps, previously described in the literature on cross-cultural adaptation, we have also included a step to verify the face validity of the coparenting instrument. The face validity of an instrument is examined to discover whether the respondents (or other lay observers) consider that the items used in the instrument evaluate the intended construct. Thus, face validity reflects the credibility of the instrument items for the respondents (Pacico, 2015; Urbina, 2007).

The first task in the process of developing a new version of an instrument, so that it is semantically equivalent to the original instrument, requires the translation and back-translation of the instrument by several professionals who have experience in the languages of both the original and target cultures. The second phase of evaluating and improving semantic equivalence, together with conceptual, cultural and idiomatic equivalence, is carried out by a committee of experts, composed of methodologists, professionals in the field of study, language professionals and some of the translators and back-translators. The role of the committee is to compare all the translated and back-translated versions of the instrument and to reach a consensus about how to resolve the discrepancies (Beaton et al., 2000).
In addition, the wording of each item must be examined and altered, as necessary, so that each item is as fully equivalent to the original item as possible. At the end of this process, a new version of the instrument is produced, that will be used in the final phase of testing and adaptation. To assess the operational, measurement and face validity equivalence of the instrument being developed, it is then examined by individuals who fit the profile of the target population for which the instrument is being prepared (Herdman et al., 1998).

The objective of this article was to describe the process of cross-cultural adaptation of the Coparenting Relationship Scale, based on the analysis of semantic, conceptual, cultural, idiomatic, operational, and measurement equivalence and the face validity of a Brazilian version of this instrument.

\section{Method}

\section{Participants}

This study was divided into seven steps (see Figure 1), involving two research groups (G1 and G2), one located in the southeast and the other in the south of Brazil.

The first step in developing a Brazilian version of the Coparenting Relationship Scale involved translating it into Brazilian Portuguese. Five people translated the instrument for G1 (four psychologists with high levels of English proficiency and a professional with a degree in Languages), and two people with good knowledge of English translated the instrument for G2. Another version of this instrument, in European Portuguese, was used by both research groups and a Brazilian version developed by Böing (2014) was used by G2, as additional translations. Next, each research group prepared a new version of the scale, after comparing the translations. In G1, this task was performed by a psychologist whose mother tongue is English and who is also fluent in Portuguese, together with a psychologist whose mother tongue is Portuguese and who also has good proficiency in English. In G2, this task was carried out by a psychology graduate student who has good knowledge of the English language.

In G1, the back-translations (Step 2) were performed by a bilingual person (whose mother's native language was English and whose father's native language was Portuguese) and by a native English-speaker who has a degree in teaching English as a Second Language, and who is fluent in Portuguese. The analysis of the back-translations was performed 
Research Group 1

Research Group 2

\begin{abstract}
$\downarrow$
Step 1 - Translation of the original instrument and synthesis of the translations

5 translators and 2 researchers

2 translators and 1 researcher

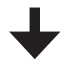

Step 2 - Back-translation and analysis of back-translations

2 translators and 1 researcher

1 translator and 1 researcher

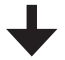

Step 3 - Assessment of semantic, conceptual, cultural and idiomatic equivalences

4 researchers

5 researchers

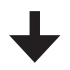

Step 4 - Assessment of operational equivalence

4 participants ( 2 couples with at least one child between 3 and 6 years of age)

Step 5 - Assessment of face validity

50 participants (25 fathers and 25 mothers with at least one child 3 to 6 years of age)

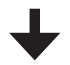

Step 6 - Construction of a unified version of the CRS

4 participants (2 researchers from each research group)

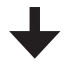

Step 7 - Measurement equivalence of the unified version

342 participants (171 mothers and 171 fathers with at least one child 4 to 6 years of age)
\end{abstract}

Figure 1. Flowchart of the steps taken in the cross-cultural adaptation of the Coparenting Relationship Scale (CRS).

by psychology professor who is fluent in Portuguese and whose native language is English. In G2, the back-translation was performed by a psychologist with good knowledge of English and the analysis of the material produced was performed by a second psychologist, who is fluent in English.

Each research group organized a committee of experts (Step 3), which had the task of examining and improving the semantic, conceptual, cultural, and idiomatic equivalence of the instrument. In G1, this committee was composed of four psychologists (three of them with a doctorate) and in G2, there were five psychologists (three of them with a doctorate).

The assessment of operational equivalence (Step 4), conducted by G1, involved the participation of two couples who had at least one child between 3 and 6 years of age and in which both the man and the woman worked outside the home and both of them resided with the child. Next, the face validity of the instrument (Step 5) was examined, considering information obtained from 25 couples (50 participants), who had at least one child between 3 to 6 years of age. The average age of the participants was 36.9 years $(s d=6.14)$, they worked 8.2 hours a day, on average $(s d=2.22)$, and the couples had been together for 10.7 years, on average ( $s d$ $=4.30$ ). Half of the participants had completed tertiary level studies.

A comparison of the instruments developed by each research group (Step 6) was carried out by four psychologists (a psychology professor and a graduate student in psychology from each research group). Finally, measurement equivalence (Step 7) was evaluated with a sample of 171 couples (342 participants) who had at least one child between 4 to 6 years of age. 
The average age of the participants was 36.6 years $(s d=$ 6.44) and the couples had been together for 10.5 years, on average $(s d=4.41)$. About half of the participants (56.4\%) had completed higher education, and their average working hours varied from 0 to 90 hours a week.

\section{Instrument}

The Coparenting Relationship Scale (CRP) is a self-report instrument. It is comprised of 35 items divided into seven subscales: Coparenting Agreement, Coparenting Closeness, Coparenting Support, Endorsement of Partner's Parenting, Division of Labor, Coparenting Undermining, and Exposure to Conflict. The items for the Exposure to Conflict subscale uses a seven-point frequency-scale that ranges from 0 (never) to 6 (very often - several times a day). The other subscales are assessed using a seven-point agreement-scale, that ranges from 0 (not true of us) to 6 (very true of us).

\section{Procedures}

As shown in Figure 1, in addition to the first four steps based on the procedures proposed by Beaton et al. (2000), Herdman et al. (1998) and Reichenheim and Moraes (2007), carried out independently by each of the research groups, the face validity of the instrument developed by G1 was verified (Step 5), the versions developed by each group were unified (Step 6) and measurement equivalence was assessed by G2, using the unified, Brazilian version of the Coparenting Relationship Scale (Step 7).

The first step of the cross-cultural adaptation process involved the translation of the CRS. Both in G1 and G2, each translator received printed material with a brief presentation of the coparenting theory, followed by a three-column table. In the first column, CRS information (title, instructions, items and scoring scales) was displayed in English. In the second column, which was blank, the translator would translate this information into Portuguese. In the third column, the translator could note any concerns or comments. In each research group, the translated versions of the instrument were analyzed, and each group prepared a first version of the Coparenting Relationship Scale.

For the back-translation of the instrument (Step 2), participants of both research groups received a form similar to the one described above, to translate the Brazilian version of the instrument developed in each group (title, instructions, items and scoring scales) back into English. The English versions were then compared with the original version (in English), and based on the discrepancies, each group modified its version of the CRS (in Portuguese).

Next, each research group held a meeting with a committee of experts (Step 3) to examine and improve the equivalence of the adapted versions (developed at the end of Step 2) with respect to the original version. Participants were given a form with a brief presentation of the coparenting theory and a table with spaces indicated for the assessment of semantic, conceptual, cultural and idiomatic equivalence of the items, instructions, and the rating scales used in the instrument.

To determine the operational equivalence of the instrument (Step 4), participants were individually interviewed to obtain information about any doubts or difficulties they had in understanding the items or instructions of the Brazilian version of the instrument. Suggestions to improve the wording of the items were noted and, based on the information collected, adjustments were made to the instrument.

To analyze the face validity of the instrument (Step 5), researchers from G1 initially recruited participants from elementary schools in the city of São Carlos. Additional families were located by indication of the initial participants, using the Snowball Technique (Sadler, Lee, Lim \& Fullerton, 2010). Two interviewers visited each couple, so that the CRS could be applied during separate and simultaneous interviews with each member of the couple. In order to evaluate the face validity of the CRS, participants gave their opinion about whether or not the behavior described in each item influences the coparenting relationship, whether the impact is positive (helpful) or negative (hindering) and indicated the strength of this influence using a scale ranging from 1 (it helps/binders just a little) to 10 (it helps/binders in a very significant way). In addition, the interviewer asked the participants to give examples for six pre-selected items, cycling through the items from one interview to the next, in order to obtain examples for all the items.

To develop a unified version of the CRS (Step 6), the two research groups made contact ${ }^{1}$ and then compared their versions of the instrument. The differences were analyzed, and a unified version of the CRS was developed at the end of this step, which was used in the final step, to evaluate measurement equivalence.

Participants of the measurement equivalence assessment (Step 7) were recruited in elementary

\footnotetext{
1 Members of the two research groups met at a Brazilian research conference, where they learned that both groups were carrying out a cross-cultural adaptation of the Coparenting Relationship Scale.
} 
schools in cities of the Southern region of the country. The remaining families were contacted via indications provided by the initial participants. The CRS was answered during an individual interview at a location chosen by each participant (his or her home, the child's school or the Psychological Assistance Service at the Federal University of Santa Catarina).

\section{Data analysis}

The information obtained in Steps 1 to 4 and in Step 6 were examined based on qualitative analysis procedures, by gathering information from different informants to improve the wording of the items of the Brazilian version of the CRS.

To analyze the examples given by the respondents for each item of the instrument, in Step 5, for the analysis of face validity, two judges reached a consensus about whether each example referred to the coparenting behavior described in the item. To verify participants' perceptions of the influence of the behaviors described in the items on the establishment of the coparenting relationship, we tallied the number of participants who believed that the behavior described was helpful in establishing a positive coparenting relationship, the number who believed the influence exerted was negative and the number who believed there was no influence. In addition, the average impact rating was calculated for items viewed as having a positive or as having a negative influence.

In order to analyze the precision of the Coparenting Relationship Scale, in Step 7, the internal consistency values for each subscale were determined by calculating Cronbach's alpha since, according to Bland and Altman (1997), it is possible to calculate these values for sets of two or more items. Alpha values equal to or greater than .70 were considered as evidence that the subscale has good precision (Urbina, 2007).

\section{Ethical considerations}

The authors of the CRS were contacted as a first step in planning this research, and they agreed that their instrument could be adapted for use in Brazil. All efforts were made to act in accordance with resolution number 466, published on December 12, 2012, and the research projects that gave rise to this study were approved by the Ethics Committees for Research with Human Beings (approval no. 674.525 and approval no. 1.514.798). Both the professionals who participated in the adaptation stages of the instrument and the couples who were interviewed received information about the goals and conditions of the study, before signing the Informed Consent Form. Confidentiality of the information obtained was ensured, as was the anonymity of the couples who were interviewed.

\section{Results}

Translation, Back-translation and Assessment of Semantic, Conceptual, Cultural and Idiomatic Equivalences

At each step of the cross-cultural adaptation process, adjustments were made to the instruments being developed by G1 and G2. With regards to semantic equivalence, grammatical changes were made in the wording of some items or instructions. For example, in Item 3, "My partner asks my opinion on matters related to parenting", the word "parenting" was replaced with "parenting roles". Other items were also slightly reworded, to ensure they referred to observable behaviors, such as Item 13, "My partner does not trust my abilities as a mother", which became, "My partner demonstrates that he does not trust my abilities as a mother".

During the evaluation of conceptual equivalence, it became apparent that, in the English language, "my partner" and "child" refer to people of both genders (male and female), but this is not the case in the Portuguese language. To deal with this, the expression "nosso(a) filho(a)" was chosen as the translation for the word "child", to be able to use the instrument with participants who had children of either gender. With respect to the word "partner", however, both G1 and G2 developed two versions of the CRS, one for each gender, to avoid using items that referred to children and parents of each gender (four different situations). The decision to use gender-specific forms is in keeping with the European-Portuguese adaptation of this instrument.

With respect to the assessment of cultural equivalence, the committee members considered that all the items described behaviors that can occur in Brazilian coparenting relationships. Finally, when examining idiomatic equivalence, the idiomatic expression "dirty work" (Item 5), which had been translated as "trabalho dificil" (difficult work), was altered to "trabalho pesado" (heavy work). The expression "at my wits end" (Item 26) was also flagged, but one of the translations, "no meu limite" (at my limit), corresponds well to the original expression. 


\section{Operational Equivalence Assessment}

After the instrument was tested for operational equivalence, the following changes were introduced: (a) inclusion of the word "satisfied" in Item 17, as one of the participants had difficulty understanding this item, and (b) maintain the use of the word "prejudica" (harms), but add the word "sabota" (sabotages) in Item 22 , instead of "mina" (undermines), in order to facilitate participants' understanding.

\section{Face Validity Assessment}

Item comprehension. The examples given by the participants for each CRS item indicate that they clearly understood the items. Although a few respondents provided examples that were not specific to the item they had been asked to illustrate, all of their examples involved coparenting. Furthermore, only one participant was unable to think of an example, at the time of the interview, for one of the items (Item 14, "My partner demonstrates being sensitive to the feelings and needs of our child"), but he considered that this item described a coparenting behavior. Given that the participants interpreted the instrument items correctly, this meant that the instrument developed using cross-cultural adaptation techniques was clearly understood and did not need to be further modified.
Behaviors that influence coparenting. Participants indicated whether they thought the behaviors described in each item helped, hindered or had no effect on the ability of parents to work together to raise their children. These responses were used to assess the degree to which Brazilian parents considered that the behaviors described in the original instrument applied to the Brazilian context. For each of the CRS items described by Feinberg et al. (2012) as corresponding to positive dimensions of coparenting, $82 \%$ to $100 \%$ of the Brazilian participants agreed that these behaviors would have a positive influence on interactions between parents. On a scale from 1 to 10, the average rating of the positive impact of each of these behaviors ranged from 7.5 to 9.6. Similarly, for the items described by Feinberg et al. as corresponding to negative dimensions of coparenting, $76 \%$ to $100 \%$ of the Brazilian participants reported that they believed the behaviors described in these items would negatively influence interactions between parents, with negative impact ratings ranging from 5.8 to 9.7 .

\section{Development of a Unified Version of the CRS}

After comparing the two versions of the CRS prepared by each research group, changes were made

Table 1

Items with Wording Differences in the two Brazilian Adaptations of the CRS and the Wording Adopted in the Unified Version of the Instrument for use in Brazil

\begin{tabular}{|c|c|c|c|}
\hline Original & Research Group 1 & Research Group 2 & Unified Version \\
\hline $\begin{array}{l}\text { 5. My partner likes to play } \\
\text { with our child and then } \\
\text { leave the dirty work to me. }\end{array}$ & $\begin{array}{l}\text { Meu parceiro gosta de } \\
\text { brincar com nosso (a) filho(a) } \\
\text { e deixa para mim o trabalho } \\
\text { pesado. }\end{array}$ & $\begin{array}{l}\text { Meu companheiro gosta de } \\
\text { brincar com nosso (a) filho(a) } \\
\text { e deixar o trabalho sujo } \\
\text { para mim. }\end{array}$ & $\begin{array}{l}\text { 5. Meu companbeiro gosta de } \\
\text { brincar com nosso (a) filho(a) } \\
\text { e deixa para mim 0 } \\
\text { trabalho pesado. }\end{array}$ \\
\hline $\begin{array}{l}\text { 6. My partner and I have } \\
\text { the same goals for our } \\
\text { child. }\end{array}$ & $\begin{array}{l}\text { Meu parceiro e eu temos as } \\
\text { mesmas metas para nosso(a) } \\
\text { filho(a). }\end{array}$ & $\begin{array}{l}\text { Eu e meu companbeiro temos } \\
\text { os mesmos objetivos para o(a) } \\
\text { nosso(a) filho(a). }\end{array}$ & $\begin{array}{l}\text { Meu companheiro e eu temos } \\
\text { as mesmas metas para } \\
\text { nosso(a) filho(a). }\end{array}$ \\
\hline $\begin{array}{l}\text { 7. My partner still wants } \\
\text { to do his or her own } \\
\text { thing instead of being a } \\
\text { responsible parent. }\end{array}$ & $\begin{array}{l}\text { Meu parceiro ainda faz suas } \\
\text { próprias coisas e não assume } \\
\text { algumas responsabilidades } \\
\underline{\text { de pai. }}\end{array}$ & $\begin{array}{l}\text { Meu companbeiro ainda quer } \\
\text { fazer suas próprias coisas } \\
\text { ao invés de ser um } \\
\text { pai responsável. }\end{array}$ & $\begin{array}{l}\text { Meu companheiro ainda quer } \\
\text { fazer suas próprias coisas } \\
\text { ao invés de ser um } \\
\text { pai responsável. }\end{array}$ \\
\hline $\begin{array}{l}\text { 22. My partner } \\
\text { undermines my parenting. }\end{array}$ & $\begin{array}{l}\text { Meu parceiro prejudica } \\
\text { minha atuacãa como mãe. }\end{array}$ & $\begin{array}{l}\text { Meu companheiro sabota meu } \\
\text { papel de mãe. }\end{array}$ & $\begin{array}{l}\text { Meu compan heiro sabota } \\
\text { (prejudica) meu papel de mãe. }\end{array}$ \\
\hline
\end{tabular}


Table 2

Precision of the Unified Version of the Coparenting Relationship Scale

\begin{tabular}{lcc}
\hline \multicolumn{1}{c}{ Subscale } & Number of items & Cronbach's Alpha \\
\hline Coparenting Support & 6 & .83 \\
Exposure to Conflict & 5 & .81 \\
Endorsement of Partner's Parenting & 7 & .78 \\
Coparenting Undermining & 6 & .72 \\
Coparenting Agreement & 4 & .68 \\
Coparenting Closeness & 5 & .46 \\
Division of Labor & 2 & .16 \\
\hline
\end{tabular}

to items $3,5,6,7,12,14,17,20$ and 22 to improve the linguistic quality of the translation and to develop a unified version of the CRS. The items with the greatest discrepancies between the two versions are presented in Table 1.

\section{Measurement Equivalence Assessment}

The internal consistency of each subscale of the unified version of the CRS, determined using a sample of 171 couples (342 participants), are shown in Table 2. Four subscales (Exposure to Conflict, Endorsement of Partner's Parenting, Coparenting Support and Coparenting Undermining) had Cronbach's alpha values that exceeded the recommended value of .70 . However, the other three subscales (Coparenting Agreement, Coparenting Closeness and Division of Labor) had alpha values that were below .70 .

\section{Discussion}

A difficult task in psychology is to distinguish relatively invariant or universal factors ("nature") from sociocultural factors ("nurture"), which result in the different expressions of human needs. The coparenting relationship involves both of these elements, and therefore, the utility of an instrument with good psychometric properties is evidenced when such a measure can be adapted for use in other countries where the cultural environment is different. The CRS was created in the United States and has already been adapted for use in Portugal by Lamela, Figueiredo and Feinberg (personal communication with D. J. P. V. Lamela on January 10, 2014). The objective of the current study was to carry out a cross-cultural adaptation and analyze evidence concerning the precision of this instrument for the Brazilian population.
Although various authors (Beaton et al., 2000; Herdman, Fox-Rushby, \& Badia, 1998; Machado, 2013; Reichenheim, \& Moraes, 2007) have explained the importance of carrying out a cross-cultural adaptation process before using an instrument that was developed in another culture, many researchers in the field do not follow the recommended procedures, which may compromise the accuracy of the information obtained using these instruments (Macuglia, Almeida, Santos, \& Giacomoni, 2016).

In view of the importance of the cross-cultural adaptation process to develop high quality instruments, the tasks undertaken in this study included the assessment of semantic, conceptual, cultural, idiomatic, operational and measurement equivalence, and two additional steps: one to verify the face validity of the adapted instrument (if it appears to assess the construct it is intended to measure, in this case, coparenting) and the other to construct a unified version of the instrument, based on the perceptions of participants from two different regions of Brazil.

A first source of evidence that the behaviors described in the Coparenting Relationship Scale also occur in Brazilian coparenting relationships was obtained, based on the conclusions of the two expert committees. This result fits with a universalist approach to cross-cultural research. These theorists claim that many behaviors occur in different cultures with equivalent social functions, although there may be variations in the form, frequency or intensity of these behaviors (Herdman, Fox-Rushby and Badia 1997; Segall et al., 1998).

Evidence of the face validity of the Brazilian version of the CRS also points to the equivalence between coparenting behaviors described in the original instrument and those that occur among Brazilian parents. Participants were able to provide examples of each 
behavior, they agreed with Feinberg et al. (2012) with respect to the positive or negative nature of the impact of each behavior on coparenting, and they indicated that these behaviors have a relatively strong influence on how couples interact, with respect to raising their children. These results provide evidence that Feinberg's model of coparenting, on which the instrument was based, is also relevant for the Brazilian context.

The construction of a unified version of the CRS for the Southern and Southeastern regions of Brazil contributed to eliminating vague linguistic terms and to reaching a consensus about the best translation for colloquial expressions in the original instrument (e.g., dirty work). These improvements are important for increasing the accuracy of the data obtained with this instrument, in future studies conducted in Brazil.

With respect to the measurement equivalence of the CRS, evidence was found indicating that four of the seven subscales had adequate precision, similar to the results found by Feinberg et al. (2012). The precision of the Coparenting Support subscale in the current study was .83 , similar to the original values, which were between .86 and .89 . The precision of the Endorsement of Partner's Parenting subscale was .78, which was also comparable to the values reported for the American parents, ranging between .61 and .88 . The precision of the Coparenting Undermining subscale was .72, which was adequate, although slightly lower than the values reported in the original study (.80 to .85). Finally, the precision of the Exposure to Conflict subscale was .81, a value in the same range as those reported by Feinberg et al., which varied between .81 and .90 .

For the Coparenting Agreement subscale, although the observed precision value $(\alpha=.68)$ in this study was slightly below the reference value $(\alpha \geq .70)$, this result is compatible with the values reported by Feinberg et al. (2012), which ranged between .66 and .74. It is possible that, with a larger sample of Brazilian participants, this problem will be resolved. According to Bland and Altman (1997), the greater the number of participants who answer an instrument, the greater the normality of the distribution for each response, and consequently, the higher the alpha values.

With respect to the Coparenting Closeness subscale, the precision $(\alpha=.46)$ was significantly below both the reference value for adequate precision and the values reported by Feinberg et al. (2012), which ranged from .75 to .83 . This result may reflect the existence of cultural differences, since according to Marôco and Garcia-Marques (2006), low alpha values may reflect differences in the grouping or relevance of the items in each culture. Given that we applied the CRS in a country that is culturally different from the one where it was developed, a confirmatory factor analysis should be conducted to determine whether the relationships among the items and each of the factors are the same for American and Brazilian parents. Some items may have a weak relationship with the factor they were expected to represent, among Brazilian parents, and some items may need to be moved to a different subscale, in comparison with the structure of the CRS that was found for American parents. For instance, given that the instrument was used with parents with preschool children, the item "Parenting has given us a focus for the future", in the Coparenting Closeness subscale, might be less relevant for Brazilian than for American couples, as a significant percentage of Brazilian parents start thinking more concretely about their children's future after they enter elementary school, while this concern appears earlier on among American parents (Santis, Barham, Coimbra \& Fontaine, 2017).

Finally, the precision of the Division of Labor subscale was very low $(\alpha=.16)$, but this subscale also presented problems in the study conducted by Feinberg et al. (2012), with correlation values ranging between .33 and .59. The working of one of these items may be a factor that resulted in the low reliability of this subscale, both in the original (US) and in the Brazilian sample. The statement, "My partner likes to play with our child and then leave the dirty work to me", for instance, includes two behaviors (playing with the child, and avoiding work). This kind of item is usually less reliable (Pacico, 2015).

Considering these hypotheses for the low precision of three of the subscales of the Brazilian version of the CRS, in future studies, it will be important to increase the sample size, analyze the internal structure of the Brazilian version of the instrument, and rewrite the items of the Division of Labor subscale. In addition, evidence concerning the validity of the Brazilian version of this instrument is also needed.

Once the CRS has been adapted for use in yet other countries, there will be greater opportunities to compare each country's specific and different cultural influences on the coparenting relationship, increasing our understanding of invariant and cultural factors present in the coparenting relationship. In addition, if professionals use adapted versions of the same instrument to assess outcomes of coparenting intervention 
programs, it will be easier to compare the results and to identify the most effective intervention strategies.

In conclusion, the cross-cultural adaptation of an instrument is important in understanding a particular phenomenon, by comparing results for different countries or in culturally different regions of a single country. After conducting the study described above, we conclude that the objective of conducting and describing the process of cross-cultural adaptation of the CRS for the Brazilian population has been achieved. As part of the adaptation process, we developed a unified version of this instrument, based on adaptations made in two different regions of the same country (Southeast and South), which allowed us to reconcile the cultural, idiomatic, conceptual, semantic and operational differences between these two regions. The adaptation process should be continued with samples from the remaining regions of Brazil (North, Northeast and Central-West), to prepare a national version of this instrument that will allow us to consider the implications of similarities and differences in patterns of coparenting, across all regions of the country.

\section{References}

Beaton, D. E.; Bombardier, C.; Guillemin, F. \& Ferraz, M. B. (2000). Guidelines for the process of cross-cultural adaptation of selfreport measures. Spine, 25(24), 3186-3191. doi: 10.1097/00007632-200012150-00014

Bland, J. M.; \& Altman, D. G. (1997). Statistics notes: Cronbach's alpha. British Medical Journal, 314, 572. doi: $10.1136 /$ bmj.314.7080.572

Biasoli-Alves, Z. M. M. (2000). Continuidades e rupturas no papel da mulher brasileira no século XX [Continuities and changes in the role of Brazilian women in the 20th century]. Psicologia: Teoria e Pesquisa, 16, 233-239. doi: 10.1590/S0102-37722000000300006

Böing, E. (2014). Relações entre coparentalidade, funcionamento familiar e estilos parentais em uma perspectiva intergeracional [Relations between coparenting, family functioning and parenting styles in an intergenerational perspective] (Doctoral dissertation, Federal University of Santa Catarina). Retrieved from https:/ / repositorio.ufsc.br/handle/123456789/128737

Carvalho, T. R., \& Barham, E. J. (2016). Instrumentos para avaliar a coparentalidade: uma comparação de suas propriedades psicométricas [Instruments for assessing coparenting: A comparison of their psychometric properties]. Avaliação Psicológica, 15(2), 207-215. doi: 10.15689/ap.2016.1502.09

Feinberg, M. E. (2002). Coparenting and the transition to parenthood: a framework for prevention. Clinical Child and Family Psychology Review, 5(3), 173-195. Retrieved from https://www.ncbi.nlm.nih.gov/ pmc/articles/PMC3161510/

Feinberg, M. E. (2003). The internal structure and ecological context of coparenting: A framework for research and intervention. Parent: Science and Practice, 3(2), 95-131. doi: 10.1207/S15327922PAR0302_01

Feinberg, M. E., Brown, L. D., \& Kan, M. L. (2012). A multi-domain self-report measure of coparenting. Parent: Science and Practice, 12(1), 1-21. doi: 10.1080/15295192.2012.638870

Frizzo, G. B., Kreutz, C. M., Schmidt, C., Piccinini, C. A., \& Bosa, C. (2005). O conceito de coparentalidade e suas implicações para a pesquisa e para a clínica [The concept of coparenting: Implications for research and clinical practice]. Revista Brasileira de Crescimento e Desenvolvimento Humano, 15(3), 84-94. Retrieved from http://pepsic.bvsalud.org/scielo.php?scrip$\mathrm{t}=$ sci_arttext\&pid=S0104-12822005000300010

Guillemin, F., Bombardier, C., \& Beaton, D. (1993). Cross-cultural adaptation of health-related quality of life measures: Literature review and proposed guidelines. Journal of Clinical Epidemiology, 46(12), 1417-1432. doi: 10.1016/0895-4356(93)90142-N

Herdman, M., Fox-Rushby, J., \& Badia, X. (1997). "Equivalence" and the translation and adaptation of health-related quality of life questionnaires. Quality of Life Reasearch, 6, 237-247. doi: 10.1023/A:1026410721664

Herdman, M., Fox-Rushby, J., \& Badia, X. (1998). A model of equivalence in the cultural adaptation of HRQoL instruments: The universalist approach. Quality of Life Research, 7(4), 323-335. doi: 10.1023/A:1024985930536

Machado, I. M. J. (2013). Adaptação transcultural para o Brasil de duas escalas de aderencia de pacientes à bemodiálise [Transcultural adaptation of two scales to evaluate adherence to hemodialysis, in Brazill (Master's thesis, Federal University of São João del-Rei). Retrieved from http://www.ufsj.edu.br/portal2-repositorio/File/mestradopsicologia/Selecao\%202015/ aaDISSERt.pdf 
Macuglia, G. R.; Almeida, R. M. M.; Santos, F. C.; \& Giacomoni, C. H. (2016). Behavioural Assessment of the Dysexecutive Syndrome (BADS): Adaptação e evidências de validade [Behavioral Assessment of the Dysexecutive Syndrome (BADS): Adaptation and Evidence of Validity]. Psico-USF, 21(2), 219232. doi: $10.1590 / 1413-82712016210201$

Marôco, J.; \& Garcia-Marques, T. (2006). Qual a fiabilidade do alfa de Cronbach? Questões antigas e soluções modernas? [How reliable is Cronbach's alpha? Old issues and modern solutions?]. Laboratório de Psicologia, 4(1), 65-90. Retrieved from http://hdl.handle.net/10400.12/133

Pacico, J. C. (2015). Como é feito um teste? Produção de itens [How is a test created? The production of items]. In C. S. Hutz, D. R. Bandeira, \& C. M. Trentini (Eds.), Psicometria (pp.55-70). Porto Alegre: Artmed.

Reichenheim, M. E., \& Moraes, C. L. (2007). Operacionalização de adaptação transcultural de instrumentos de aferição usados em epidemiologia [Operationalizing the cross-cultural adaptation of epidemological measurement instruments]. Revista de Saúde Pública, 41, 665-673. doi: 10.1590/ S0034-8910200600500003
Sadler, G. R., Lee, H., Lim, R. S. \& Fullerton, J. (2010). Recruitment of hard-to-reach population subgroups via adaptations of the snowball sampling strategy. Nursing and Health Sciences, 12, 369-374. doi:10.1111/j.1442-2018.2010.00541.x

Santis, L., Barham, E. J., Coimbra, S., \& Fontaine, A. M. G. V. (2017). Envolvimento paterno: validade interna da versão brasileira do Inventory of Father Involvement [Father involvement: Internal validity of the Brazilian version of the inventory of Father Involvement]. Avaliação Psicológica, 16(2), 225-233. doi: 10.15689/ap.2017.1602.13

Segall, M. H., Lonner, W. J., \& Berry, J. W. (1998). Cross-cultural psychology as a scholarly discipline: On the flowering of culture in behavior research. American Psychologist, 53(10), 1101-1110. doi: 10.1037/0003-066X.53.10.1101

Urbina, S. (2007). Fundamentos da Testagem Psicológica [Fundamentals of Psychological Testing]. Porto Alegre: Artmed.

Recebido em: 05/09/2016

Reformulado em: 27/01/2017 Aprovado em: 10/04/2017 
Nota dos autores:

Agradecimentos à Coordenação de Aperfeiçoamento de Pessoal de Nível Superior (Capes) e à Fundação de Amparo a Pesquisa do Estado de São Paulo (FAPESP - processo n 2014/00186-0) pelo financiamento da bolsa de mestrado à Thaís Ramos de Carvalho. Ao CNPq pela concessão de bolsa de produtividade aos pesquisadores Maria Aparecida Crepaldi e Mauro Luís Vieira. À CAPES pela concessão de bolsa de doutorado à Carolina Duarte de Souza

About the authors:

Thaís Ramos de Carvalho: Master in Psychology from the Federal University of São Carlos (UFSCar) and doctoral student in the Graduate Program in Psychology of the Federal University of São Carlos.

E-mail: thais_rcarvalho@hotmail.com

Elizabeth Joan Barham: PhD in Social and Development Psychology from the University of Guelph and professor of the Post-Graduation Program in Psychology, Federal University of São Carlos (UFSCar).

E-mail: lisa.barham.ufscar@gmail.com

Carolina Duarte de Souza: PhD in Psychology from the Federal University of Santa Catarina (UFSC) and Substitute Professor at the Psychology Department at the Federal University of Santa Catarina.

E-mail: carolzunino@gmail.com

Elisangela Böing: PhD in Psychology from the Federal University of Santa Catarina (UFSC) and professor at the Psychology Department of the Federal University of Santa Catarina.

E-mail: elisangelaboing@gmail.com

Maria Aparecida Crepaldi: PhD in Mental Health from UNICAMP and professor of the Graduate Program in Psychology, Federal University of Santa Catarina (UFSC).

E-mail: maria.crepaldi@gmail.com

Mauro Luís Vieira: PhD in Experimental Psychology from the University of São Paulo (USP) and professor of the Graduate Program in Psychology at the Federal University of Santa Catarina (UFSC).

E-mail: maurolvieira@gmail.com

Contato com os autores:

Thaís Ramos de Carvalho

Programa de Pós-Graduação em Psicologia da Universidade Federal de São Carlos

Rodovia Washington Luís, km 235, SP-310

CEP: 13565-905

São Carlos-SP, Brasil 